\title{
CARACTERIZAÇÃO NUTRICIONAL DE FARINHA DE DUAS VARIEDADES DE BATATA DOCE E ENRIQUECIDA COM ACIDO ASCÓRBICO
}

\author{
A. A. C. PAGANI ${ }^{1}$; A. C. P. SIQUEIRA ${ }^{1}$; A. M. SANTOS ${ }^{1}$; J.M. SANTOS $^{1}$; C. C.S. BERY ${ }^{2}$; \\ G.F.SILVA ${ }^{2}$ \\ ${ }^{1}$ Universidade Federal de Sergipe, Departamento de Tecnologia de Alimentos \\ ${ }^{2}$ Universidade Federal de Sergipe, Núcleo de Graduação em Engenharia de Petróleo \\ *e-mail: alespagani@yahoo.com.br
}

\begin{abstract}
RESUMO
A batata doce (Ipomoea batatas), é um dos alimentos mais nutritivos, pois possui carboidrato complexo de baixo índice glicêmico, rica em fibras, ferro, vitamina $\mathrm{C}$ e potássio, além de apresentar alto teor de vitamina E. Esta planta originária da América Tropical, é uma das tuberosas mais populares do Brasil. O aproveitamento agroindustrial desse tubérculo constitui uma alternativa de reduzir as perdas pós-colheita, além de agregar valor à matéria-prima. Diante do exposto, o objetivo deste trabalho foi de obter um produto em forma de farinha de duas variedades de batata-doce, ou seja, a roxa e a branca, realizando a caracterização nutricional, além de enriquece-la com $1 \%$ de ácido ascórbico. Todas as análises foram realizadas em triplicatas de acordo com as normas do Instituto Adolfo Lutz, (2005) e AOAC (1980). Conclui-se que as farinhas das duas variedades de batata doce, apresentaram significativo teor nutricional, e que a formulada com $1 \%$ de ácido ascórbico, mesmo após a secagem apresentou um alto teor ácido ascórbico.
\end{abstract}

\section{INTRODUÇÃO}

A Batata doce (Ipomea batatas L.) é uma hortaliça que apresenta um elevado grau de rusticidade e uma gama de potencialidade para seu uso, sendo uma espécie de interesse econômico principalmente, para países em desenvolvimento e com escassez de alimentos para a população (FIGUEIREDO, 1995). A maior parte de sua comercialização é realizada por meio de agentes intermediários que dá resultado numa menor margem de lucro para os agricultores e com isso desestimulando seu plantio (SILVA, 2010).

A batata doce participa do suprimento de calorias, vitaminas e minerais na alimentação humana. As raízes apresentam teor de carboidratos variando entre $25 \%$ a $30 \%$, dos quais $98 \%$ são facilmente digestíveis. Também são excelentes fontes de carotenóides, vitaminas do complexo B, potássio, ferro e cálcio. Suas raízes são tuberosas e variam de forma, tamanho e coloração, conforme a cultivar e o meio ambiente em que são produzidas (SILVA, 2010).

Visando agregar valor ao produto e renda aos agricultores, objetivou-se a produção de farinha de batata doce, tanto da batata roxa quanto da branca, comparando assim a qualidade do produto final entre elas e as características físico-químicas.

\section{MATERIAL E MÉTODOS}

Este trabalho foi desenvolvido no Laboratório de tecnologia de Produtos de Origem Vegetal, no Laboratório de Análise de Alimentos Departamento de Tecnologia de Alimentos (DTA), Universidade Federal de Sergipe (UFS), na cidade de São Cristóvão, Sergipe, Brasil. 
Foram utilizadas duas variedades de batata doce (branca e roxa) que foram adquiridas no CEASA de Aracaju-SE.

\subsection{Processamento da batata-doce}

Inicialmente as batatas foram higienizadas, descascadas e fatiadas em um mini processador industrial. As amostras de batata branca foram divididas duas porções sendo que uma passou apenas pelo tratamento higienização (A), e a outra porção passou pelo tratamento de imersão em ácido ascórbico a $1 \% 30 \mathrm{mim}$; as batatas roxas permaneceram in natura sem tratamento (C). Em seguida foi realizada a secagem a $63^{\circ} \mathrm{C}$ por um período de 2:30 hs (duas horas e trinta minutos) em secador de bandeja em camada fina e após desidratadas foi feito a farinha (Figura 1) para posteriores análises.

Figura 1: Farinhas de batata doce, (A) Farinha de Batata doce Branca sem tratamento; (B) Farinha de Batata doce Branca com tratamento $-1 \%$ de ácido ascórbico); (C) Farinha de Batata doce Roxa sem

tratamento

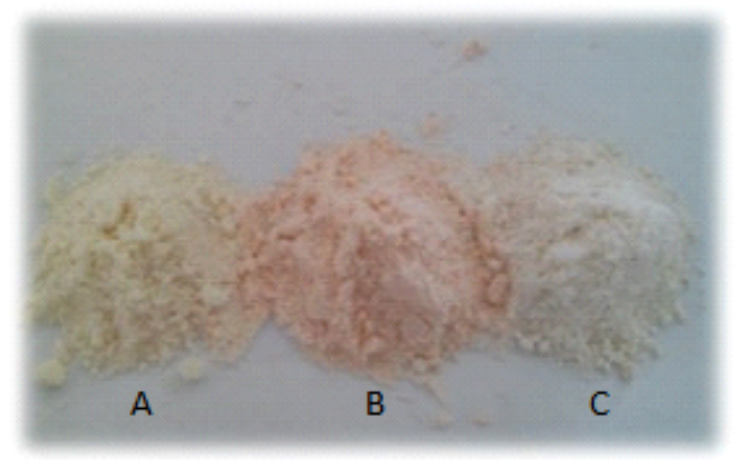

Fonte: Autor (2015)

\subsection{Rendimento}

O rendimento foi obtido por meio da pesagem da batata doce antes e após a secagem, calculando-se a razão entre a diferença multiplicada por 100 .

\subsection{Análises Físico químicas}

As amostras foram avaliadas quanto aos teores de umidade, atividade de água, cinzas, ${ }^{\circ}$ BRIX e pH. As análises físico-químicas foram realizadas em triplicata e segundo AOAC (1980).

\section{4 Ácido ascórbico}

Foi determinado de acordo com o método $\mathrm{n}^{\mathrm{o}} 43.065$ da AOAC (1984), modificado por Benassi \& Antunes (1988). No qual substitui a solução de extração de ácido metafosfórico por ácido oxálico.

\subsection{Carotenóides totais}

Os teores de carotenóides foram avaliados seguindo o método proposto por Lichtenthaler (1987) expressos em $\mu \mathrm{g} / \mathrm{g}$.

\subsection{Cor}

As leituras da cor foram obtidas com a utilização do colorímetro Color Meter Minolta 200b. No qual luminosidade (L) é um parâmetro que pode variar do zero (preto) a 100 (branco); $a^{*}$ varia de vermelho $(+a)$ a verde $(-a) ; b^{*}$ refere-se à variação de cor entre o amarelo (+b) e o azul (-b) e; ângulo Hue $\left(\mathrm{Hue}^{\mathrm{o}}\right.$ ) varia de 0 a $360^{\circ}$, sendo que o $0^{\circ}$ corresponde à cor vermelha, $90^{\circ}$ corresponde ao amarelo, $180^{\circ}$ ao verde e $270^{\circ}$ ao azul.

\section{RESULTADOS E DISCUSSÃO}

\subsection{Rendimento}

Segundo Silva (2010), os rendimentos obtidos para a farinha de bata-doce branca e roxa apresentaram rendimento de 26,3 e $24 \%$ respectivamente. Dados semelhantes foram obtidos por Carvalho et. al. (1981) para o rendimento da batata roxa, que foi de $23,5 \%$. Os resultados para rendimento obtido em laboratório foram de $24,07 \%$ para as duas variedades de batata-doce. 


\subsection{Caracterização físico química}

Os resultados dos parâmetros físicoquímicos da farinha de batata-doce estão apresentados na Tabela 1. O teor de umidade da farinha de batata-doce obtida encontrou-se dentro do valor máximo estipulado pela Anvisa (2005), que é de 15\%. Segundo Fernandes et al. (2008), farinhas com umidade acima de 14\% tendem a formar grumos, o que irá prejudicar a produção de massas por processo contínuo, além de possibilitar o desenvolvimento de microrganismos, como fungos, e a diminuição da estabilidade da farinha, já que a água é um componente essencial para que as reações químicas e enzimáticas ocorram, diminuindo assim a sua vida útil. Santos (2012) obteve farinha de batata doce pelo processo de secagem solar, a qual quantificou uma atividade de água de 0,4 , neste trabalho foi encontrado uma atividade de agua entre $0,2 \mathrm{e}$ 0,3 , este menor valor deve ser atribuído ao processo de secagem.

Tabela 1 - Parâmetros com os diferentes tipos de farinha da batata doce

\begin{tabular}{|c|c|c|c|}
\hline \multirow[t]{2}{*}{ PARAMETROS } & \multicolumn{3}{|c|}{ TRATAMENTOS } \\
\hline & A & $\mathrm{B}$ & $\mathrm{C}$ \\
\hline Umidade (\%) & $4,48 \pm 0,028$ & $4,91 \pm 1,17$ & $5,11 \pm 0,075$ \\
\hline Atividade de água (aw) & $0,22 \pm 0,04$ & $0,18 \pm 0,05$ & $0,31 \pm 0,02$ \\
\hline pH & $6,11 \pm 0,002$ & $5,41 \pm 0,004$ & $6,45 \pm 0,02$ \\
\hline 'BRIX & $28 \pm 0,008$ & $20 \pm 0,004$ & $22 \pm 0,002$ \\
\hline Cinzas (\%) & $2,86 \pm 0,007$ & $3,43 \pm 0,09$ & $2,96 \pm 0,02$ \\
\hline $\begin{array}{c}\text { Ácido } \\
\text { ascórbico(mg/100g) }\end{array}$ & $11,36 \pm 11,41$ & $90,68 \pm 0,11$ & $12,96 \pm 2,26$ \\
\hline $\begin{array}{c}\text { Carotenoides Totais } \\
\left(\mu \mathrm{g} / \mathrm{g}^{-1}\right)\end{array}$ & $50,56 \pm 0,18$ & $60,39 \pm 0,72$ & $62,5 \pm 0,36$ \\
\hline
\end{tabular}

A-Farinha de batata doce branca; B- Farinha de batata doce branca com $1 \%$ de ácido ascórbico; C- farinha de batata doce roxa.

Fonte: Autor (2015).
A determinação de cinzas realizada no laboratório encontrou o valor de 2,86 para batata doce branca, sendo semelhante com o resultado encontrado por Silva (2010) que encontrou para cinzas o valor de 2,18. A medição do $\mathrm{pH}$ encontrado para a batata roxa foi de 5,5 sendo semelhante com a encontrada no laboratório de 6,4 para o mesmo tipo de batata (Silva, 2010).

A amostra B, a qual foi adicionada $1 \%$ de ácido ascórbico, mesmo após a secagem apresentou um teor de ácido ascórbico significativo com relação as amostras $\mathrm{A}$ e $\mathrm{C}$, ou seja, 90mg/100g (B), 11,36mg/100g (A) e $12,96 \mathrm{mg} / 100 \mathrm{~g}(\mathrm{C})$.

Com relação aos carotenoides totais a farinha de batata roxa apresentou maiores teores com 62,5 $\mu \mathrm{g} / \mathrm{g}^{-1}$. Moura (2009) estudando o perfil de carotenoides totais em farinhas de batata doce de polpa alaranjada, encontrou teores de carotenoides totais entre 20,45 a 79,66 $\mu \mathrm{g} / 100 \mathrm{~g}$. Segundo RodriguesAmaya et al. (2011), a produção de farinha a partir de batata-doce aumenta a vida útil do produto e facilita sua incorporação em diversos produtos. Entretanto, existe a necessidade de otimizar as condições de processo e estocagem da farinha para reduzir a perda de carotenoides.

Os parâmetros de cor podem ser comparados partir dos resultados obtidos na análise (Tabela 2). Quando se comparou o padrão de cor de luminosidade (L) de cada uma das farinhas, a amostra (A) apresentou luminosidade mais próxima ao branco se comparada as demais amostras. Quanto à a* a amostra (C) apresentou maior proximidade a cor vermelha quando comparada as demais. Fernandes et. al. (2008) apresentou valores aproximados para a avaliação de cor da farinha de casca de batata-doce com $\mathrm{L}=$ 59,$52 ; \mathrm{a}=5,0$ e $\mathrm{b}=14,68$. Percebe-se que quando se faz a correlação dos carotenoides totais e a análise de cor das farinhas, a que contém mais carotenoides totais e a amostra C, como também o parâmetro $a^{*}$ foi o que 
numericamente teve um maior valor, este parâmetro tem uma maior proximidade a cor vermelha.

Tabela 2 - Média do resultado da avaliação de cor das farinhas da batata-doce.

\begin{tabular}{llll}
\hline & $\mathbf{L}$ & $\mathbf{a}$ & $\mathbf{B}$ \\
\hline $\mathbf{A}$ & $67,06 \mathrm{a}$ & $+2,80 \mathrm{a}$ & $+18,26 \mathrm{a}$ \\
$\mathbf{B}$ & $54,80 \mathrm{~b}$ & $+2,36 \mathrm{a}$ & $+14,73 \mathrm{~b}$ \\
$\mathbf{C}$ & $50,53 \mathrm{~b}$ & $+5,90 \mathrm{~b}$ & $+17,90 \mathrm{a}$ \\
\hline
\end{tabular}

A-Farinha de batata doce branca; B- Farinha de batata doce branca com $1 \%$ de ácido ascórbico; C- farinha de batata doce roxa.

Fonte: Autor (2015).

\section{CONCLUSÃO}

Os resultados indicaram que as duas cultivares de batata doce são viáveis para o processo de obtenção de farinha, tendo em vista que apresenta teores nutricionais significativos e que a enriquecida de $1 \%$ de vitamina $\mathrm{C}$ mesmo após o processo de secagem mantém considerável teor de ácido ascórbico.

\section{REFERÊNCIAS}

ASSOCIATION OF OFFICIAL
ANALYTICAL CHEMISTS - AOAC.
Official methods of analysis of the
Association of Official Analytical Chemists.
14. ed. Washington, DC; 1141p., 1984.

BENASSI, M. T.; ANTUNES, A. J. A comparison of meta-phosphoric and oxalic acids as extractant solutions for the determination of vitamin $C$ in selected vegetables. Arq. Biol. Tech., 31(4): 507 1988.

CARVALHO, M. P. M.; MOURA, L. L.; PAPE, G. Processo de obtenção de farinha de batata-doce. Pcsq. agropec. bras,, Brasilia, 16(4):551-556,juL/ago. 1981.

LICHTENTHALER, H.K. Chlorophylls and carotenoids: pigments of photosynthetic biomembranes. Methods of Enzymology, v.148, p.350-382. 1987.
FIGUEIREDO, A. F. Armazenamento de rama, tipos de estacas, profundidade de plantio e análise do crescimento de plantas de batata-doce (Ipomea batatas L.). 1995. 127 f. (Tese doutorado) - Universidade Federal de Viçosa, Viçosa.

MOURA, L. S. de M., SILVA, E. M. M., RANGEL, C. N., SICILIANO, I., SILVA, J. B. C., CARVAlHO, J. L.V., NUTTI, M. R. Perfil de carotenóides em farinhas de batata-doce de polpa alaranjada (Ipomoea Batatas). $3^{\mathrm{a}}$ Reunião Anual de Biofortificação no Brasil. 2009. Aracaju - Sergipe.

RODRIGUEZ-AMAYA, D. B.; NUTTI, M. R.; CARVALHO, J. L. V. Carotenoids of sweet potato, cassava, and maize and their use in bread and flour fortification. In: PREEDY, R. R.; WATSON, R. R.; PATEL, V. B. (Eds.). Flour and breads and their fortification in health and disease prevention. London; Burlington; San Diego: Academic Press; Elsevier, 2011. chap. 28, p. 301-311

SILVA, R. G. V. Caracterização físicoquimica de farinha de batata-doce para produtos de panificação. Universidade Estadual do Sudoeste da Bahia. Itapetinga, Bahia, 2010.

SANTOS, J. C., SOUZA, D.C.L., SANTANA, M. M., CASTRO, A. A., SILVA, G. F. Estudo da cinética de secagem de batata-doce (Ipomoea batatas). Revista Brasileira de Produtos Agroindustriais, Campina Grande, v.14, n.4, p.323-328, 2012. 